\title{
Human Development in the Context of Nepal
}

\section{Tulasa Devi Dulal (M. Phil.)*}

\begin{abstract}
This article tries to highlight the condition of human development in the contest of Nepal. The topic is framed as part of the general issue of gender, caste/ethnicity, regional rural and urban disparities. This study is based on descriptive as well as analytical in nature. Sources of information in this study are secondary nature like published and unpublished research papers, human development annual reports and national and international journal articles. Data are presented in to tabular form and they are analyzed in to descriptive form. The first Human Development Report was launched in 1990 by the Pakistani economist Mahbub ul Haq and Indian Nobel laureate Amartya Sen. Since then reports have been released most years, and have explored different themes through the human development approach, which places people at the center of the development process. Since 1990, the United Nations Development Programme (UNDP) has published a series of annual Human Development Reports (HDRs) in which the human development index (HDI) is computed for each country. Nepal has been publishing the Nepal Human Development Report since 1998, with the focus shifting considering the needs of the country. In the 1990-2018 period, Nepal's human development index score rose from 0.380 to 0.579 , an increase of 52.6 percent and life expectancy at birth increased by 16.1 years to 70.5 years. Notable progress in human development has taken place in Nepal. However, across gender, region and local groups, large disparities persist.
\end{abstract}

Key words: Human development, regional, gender, caste/ethnicity \& disparity.

\section{Introduction}

The human development concept was pioneered by Pakistani economist Mahbub ul Haq. At the World Bank in 1970s and later as minister of finance he argued that existing measures of human progress such as the gross domestic product provided only a partial view of how people are faring. Amartya Sen, (born November 3, 1933, Santiniketan, India) first Indian economist who was awarded the 1998 Nobel Prize in economic siences for

\footnotetext{
${ }^{*}$ Ms. Dulal is a Faculty Associate at the Department of Population Studies, Patan Multiple Campus, TU, Lalitpur. Email: tulasadulal123@gmail.com
} 
his contributions to welfare economics and social choice theory and for his interest in the problems of society's poorest members.

His publications include Development as Freedom (Oxford, 1999). Sen would say it is not quite correct to say that the Human Development Report draws on his ideas in particular it draws on the ideas of a lot of us and Mahbub himself was a great pioneer. Then Sen's book, Commodities and Capabilities, came out in 1985 and a further study called The Standard of Living, came out in 1987, based on his 1985 Cambridge lectures. Sen was getting more and more involved in all this and Mahbub was cheering him (Sen, 1987b).

The Human Development Index or HDI, embodies Amartya Sen's “capabilities" approach to understanding human well-being which emphasizes the importance of ends (like a decent standard of living) over means (like income per capita) (Sen, 1985). Mahbub ul Haq (1999) has been Drawing heavily on the capabilities approach to human welfare and "human development" project of the UNDP has been to define a new conceptualized of well-being and to make available measures of well-being based on that new idea. The first HDR (UNDP, 1990) declared that the means of development have obscured its ends because of two primary factors.

The human development process is one of enlarging people's choices. It focuses on three essential components: a long and healthy life, knowledge, and "access to resources needed for a decent standard of living" because if these essential choices are not available, many other opportunities remain inaccessible (UNDP, 1990). In the words of Paul Streeten (1994), human development puts people back at center stage, after decades in which a maze of technical concepts had obscured this fundamental vision. This is not to say that technical analysis should be abandoned. Sen, who was one of the principal consultants on HDR 1990, wrote that at first he did not see the point of a crude composite index like the HDI, especially against the backdrop of the wealth of information that the UNDP was planning to include in the report (UNDP, 1990).

UNDP launched the first annual Human Development Report (HDR) and the introduced the Human Development Index. HDR 1990 presented the concept of "human development" as progress towards greater human well-being and provided country-level data for a wide range of well-being indicators and established the HDR expanded both the availability of measurement and comparison tools used by governments, NGOs and researchers (UNDP, 2010).

Human development is concerned mainly with guaranteeing long and healthy life knowledge and quality education and a decent standard of living as well as the creation of 
conducive conditions for the people to actively participate in the political and community life environmental sustainability, protection of human rights and human security and ensuring of gender equity (Alamieyeseigha \& Kpolovie, 2013; Atkinson, 2015).

The term 'human development' may be defined as an expansion of human capabilities, a widening of choices, an enhancement of freedom and a fulfillment of human rights. At the beginning, the notion of human development incorporates the need for income expansion. However, income growth should consider expansion of human capabilities. Hence development cannot be equated solely to income expansion (Sen, 1999).

The first UNDP Human Development Report published in 1990 stated that: The basic objective of development is to create an enabling environment for people to enjoy long, healthy and creative lives. It also defined human development as a process of enlarging people's choices and strengthen human capabilities in a way which enables them to lead longer, healthier and fuller lives.

From this broad definition of human development, one gets an idea of three critical issues involved in human development interpretation. These are to lead a long and healthy life, to be educated, and to enjoy a decent standard of living. Barring these three crucial parameters of human development as a process enlarging people's choices, there are additional choices that include political freedoms, other guaranteed human rights, and various ingredients of self-respect (UNDP, 2010).

The first human development report was launched in 1990 by the Pakistani economist Mahbub ul Haq and Indian Nobel laureate Amartya Sen. Since then reports have been released most years and have explored different themes through the human development approach which places people at the center of the development process. Since 1990, the United Nations Development Programme (UNDP) has published a series of annual Human Development Reports (HDRs) in which the human development index (HDI) is computed for each country. This index has become an important alternative to the traditional multi-dimensional measure of development (i.e. health, education and income). The calculation of the index involves three dimensions: long and healthy life (assessed by life expectancy at birth) knowledge (measured by mean and expected years of schooling) and a decent standard of living (represented by income).

UNDP have been introduced Several new indices over the years in different reports, including the Human Development Index, the Gender-related Development Index, the Gender Empowerment Measure, the Human Poverty Index. The Gender-related Development Index, the Gender Empowerment Measure and the Human Poverty 
Index were removed in 2010.

The GDI (also known as Gender-related HDI) and the GEM were introduced in 1995 following the international recognition of the importance of monitoring the progress achieved towards the elimination of gender disparities to measure gender gaps within and between countries in all aspects of life, having established that there is no society in which women enjoy the same opportunities that men do. The first GDI indicators were created by the United Nations Organization (UN) within the context of the United Nations Development Programme (UNDP) (WEF, 2010).

The inclusion of the gender component into the original index has been regarded as a key limitation of the GDI in fact, the levels of the HDI mitigate the differences between men and women, which consequently seem less relevant. GDI measures women's achievements and capabilities in a broad sense, while the GEM is concerned with women's actual use of these capabilities to participate in the economic and political life, i.e., the GEM measures their empowerment (Bozzano, 2011).

The GEM is characterized by three dimensions: political participation and the associated with decision-making power (measured as the percentage of female Members of Parliament) economic participation and the associated decision-making power (given by the percentage of women among legislators, senior officials and managers and by the percentage of professional and technical positions occupied by women) and finally access to economic resources (ratio between the estimated income received by women and that received by men (UNDP, 2007).

The 2010 Report introduced a new measure of gender inequities index including maternal mortality rates and women's representation in parliaments. Nepal has been publishing the Nepal Human Development Report since 1998, with the focus shifting considering the needs of the country. Remarkable gender inequality remains and has heightened a variety of human development disparities. Reoriented human development strategies should strongly focus on achieving gender equality and reducing interprovincial disparities including through provincial and local governments playing more effective roles. Remarkable progress has been made on the protection and promotion of women's rights and gender equality. Still, deeply rooted socio-cultural norms impede better outcomes. The depths of gender inequality is much broader than what human development indices capture. 


\section{Objectives}

The overall objective of this study is to review the national and international human development reports, policies and practices regarding the regional, gender and caste/ ethnicity agenda. The specific objective of this study is to study the conditions of human development in the context of Nepal.

\section{Methodology}

This study used secondary data for the analysis. The HDI of National planning commission Nepal and collected from human development report 2014. This study primarily builds upon desk reviews of human development report, journals, paper and grey articles. The desk review fallows the major discourses that influence the gender, regional and gender mainstreaming agenda. Data sources comprised the Central Bureau of Statistics for life expectancy at birth, mean years of schooling and the adult literacy rate and the National Accounts of Nepal (Central Bureau of Statistics) for GNI per capita (PPP \$).

\section{Human Development Report in the Context of Nepal}

Nepal has been publishing the Nepal Human Development Report since 1998, with the focus shifting considering the needs of the country. The last Nepal human development report in 2014 focused mainly on the human capability approach to development. Since then, changes has been occurred in the political, economic, social and governance spheres. With the promulgation of the new Constitution in 2015 and its successive enforcement, the country has moved to a federal system in political sector with three levels of government. The Constitution guaranteed the fundamental rights of the people (UNDP, 2014).

Therefore, the Nepal Human Development Report 2020, Beyond LDC Graduation expressed that productive transformation and prosperity has focused on how Nepal could meaningfully advance towards sustainable human development at a faster pace. The Government of Nepal has set a long-term vision of a "Prosperous Nepal and Happy Nepali". The current 15th five-year Plan has internalized the Sustainable Development Goals (SDGs) in its policies and programmes, and commits to transforming Nepal into a developing country category from a least developed country (LDC) (UNDP, 2020).

\section{Human Development and Social Exclusion/Inclusion}

According to the human development report 2016 stated the concepts of social inclusion is a sense of the distribution of well-being, reduction in inequality and poverty and the 
availability and distribution of opportunities factors into the process through which growth or development happens. Inclusive growth is seen as reducing disadvantages, expanding opportunities and discouraging exclusion and is non-discriminatory practices. Inclusive development subsumes non-income dimensions of well-being and includes distribution not only across individuals but also across groups differentiated by gender, ethnicity, regional location and so on. The hallmarks of inclusive growth are wider participation and benefit sharing and the breaking of discriminatory barriers to create a more level playing field (UNDP, 2016).

Since the adoption of democracy in 1990, Nepal has pursued several strategies to address multi-dimensional human development and inclusivity and growth. The present political transition not with standing the efforts of the Government supported by development partners have broadly been to accelerate aggregate growth through investments in social and physical infrastructure and create enabling institutional mechanisms. Efforts are also ongoing to develop the rule of law and the democratic character of institutions at all levels. However, structural problems related to control over and access to resources remain largely unaddressed (UNDP, 2014).

Nepal moved up two spots to rank 147 out of 189 countries in 2019 Human Development Index, according to the report. While South Asia was the fastest-growing region with 46 percent growth in the 1990-2018 period. Nepal's human development index rose from 0.380 to 0.579 an increase of 52.6 percent. This reflects that on average people are living longer are more educated and have greater income (UNDP, 2020).

For example, between 1990 and 2018, Nepal's life expectancy at birth increased by 16.1 years to 70.5 years, mean years of schooling increased by 2.8 years and expected years of schooling increased by 4.7 years. Nepal's Gross National Income per capita increased by about 130.5 percent between $1990(\$ 1,192)$ and $2018(\$ 2,748)$. It, however, is still below the average value of 0.634 for countries in the medium human development group and below the average of 0.642 for countries in South Asia (UNDP, 2020).

UNDP and Government of Nepal had calculated the 2011 census data to get the human development index value for Nepalese people. They used 2011 census data for health education and income indicators. HDI values by district are calculated using the 2011 latest available data. New national accounts estimates of the Central Bureau of Statistics (CBS, 2011) for per capita GNI in PPP\$. Data from the 2011 National Living Standards Survey have been used to compute income for caste and ethnic groups. HDI was based on the arithmetic mean. Some highest and lowest HDI value of districts are as fallows. 
Among the ecological regions, the Hills has high continue to lead with an HDI score of 0.569 , followed by the Tarai at 0.521 , a pat-tern seen in 2001 as well as 2006 . The pace of HDI improvement has been faster in the Mountains from 0.436 in 2006 to 0.496 in 2011. In spite of its relatively low HDI score, the Mid Western development region has made some gains from 0.452 in 2006 to 0.503 in 2011 (UNDP, 2014).

Table 1: Districts with the highest and lowest HDI scores, 2001 and 2011

\begin{tabular}{|l|l|l|l|l|l|l|l|}
\hline \multicolumn{4}{|c|}{ Highest } & \multicolumn{4}{c|}{ Lowest } \\
\hline $\mathbf{2 0 0 1}$ & \multicolumn{2}{|l|}{$\mathbf{2 0 1 1}$} & $\mathbf{2 0 0 1}$ & $\mathbf{2 0 1 1}$ \\
\hline Kathmandu & 0.652 & Kathmandu & 0.666 & Mugu & 0.304 & Bajura & 0.425 \\
\hline Bhaktapur & 0.595 & Lalitpur & 0.604 & Bajura & 0.310 & Bajhang & 0.430 \\
\hline Kaski & 0.593 & Kaski & 0.623 & Kalikot & 0.322 & Kalikot & 0.432 \\
\hline Lalitpur & 0.588 & Bhaktapur & 0.618 & Bajhang & 0.331 & Humla & 0.432 \\
\hline Rupandehi & 0.546 & Manang & 0.608 & Jajarkot & 0.343 & Achham & 0.446 \\
\hline
\end{tabular}

Source: UNDP, 2014

Table 1 shows that the district level HDI value in five highest HDI districts in 2001 are also the highest in 2011, with some changes in ranks. Rupandehi, fifth rank with HDI value (0.546) in 2001was replaced by Manang with score (0.608) in 2011. Three of the five lowest HDI districts, Bajura, Bajhang and Kalikot, are the same in 2001 and 2011. Humla and Achham replace Mugu and Jajarkot in 2011 among the districts with the lowest scores. The huge progress made by Mugu in education has helped improve its HDI ranking (UNDP, 2014).

\section{Human Development Index (HDI) Values by Caste/Ethnicity in Nepal}

Human Development Index, geometric mean values by caste and ethnicity are based on both census and Nepal Living Standards Survey information 2011. The population weights of various castes and ethnic groups have been derived from the 2011 Census per capita income data by caste and ethnic groups are calculated from the 2011 survey. Inequalities in human development by caste and ethnicity have been noted since the first Nepal Human Development Report in 1998. These remain pronounced, despite some evidence that they may be reducing over time.

Nepal human development reports 2014, have emphasized that among the three components of the HDI differences in educational attainment largely explain inequalities between high and low HDI values for caste and ethnic groups. 
Among the four major caste and ethnic clusters - the Brahmans/Chhetris, the Janajatis, the Dalits and the Muslims - the Brahmans/Chhetris rank at the top with an HDI value of Thakalis have much higher HDI scores, since the Newars mostly live in urban areas and the Thakalis due to their entrepreneurial qualities. The HDI value of caste /ethnicity are as follows:

Table 2: Human development index values by major caste and ethnic groups, 2011

\begin{tabular}{|l|c|}
\hline Major Caste/Ethnicity Groups & HDI Values \\
\hline All Brahmin/Chhetry & 0.538 \\
\hline Hill Brahmin & 0.557 \\
\hline Hill Chhetry & 0.507 \\
\hline Madhesi Brahmin/Chhetry & 0.536 \\
\hline Medhesi Other Caste & 0.460 \\
\hline All Dalit & 0.434 \\
\hline Hill Dalit & 0.446 \\
\hline Madhesi Dalit & 0.400 \\
\hline Newar & $\mathbf{0 . 5 6 5}$ \\
\hline All Janajatis Excluding Newar & 0.482 \\
\hline Hill Janajati & 0.509 \\
\hline Terai Janajati & 0.473 \\
\hline Muslim/Musalman & 0.422 \\
\hline All Hill/Mountain Groups & 0.511 \\
\hline All Tarai/Madhesi Groups & 0.454 \\
\hline Others & 0.586 \\
\hline
\end{tabular}

Source: UNDP, 2014

Table 2 shows that Newar has the highest HDI value with score 0.565 fallowed by Hill Brahmin HDI value with 0.557. And Medhesi Dalits have lowest HDI value with score 0.400 followed by Muslim HDI value 0.422 . There are significant variations within caste and ethnic clusters. The HDI score for the Hill Chhetris is 0.507 which is about 9 percent lower than that of the Hill Brahmans. There are also differences between the Tarai and Hill Janajatis. A similar picture emerges among the Dalits. Hill Dalits rank at 0.446 compared to 0.400 for the Madhesi Dalits. The HDI rank for all Hill/Mountain groups is 0.511 compared to 0.454 for all Tarai/Madhesi groups. 
Among all Janajatis and Dalits, those from the Hills have better HDI scores than those from the Tarai or Madhes. Inequalities in HDI scores linked to caste and ethnicity thus also have a geographic dimension. This is underscored by the low educational attainment of the Dalits in general and the Madhesi Dalits in particular, and of the Muslims. Low levels of education as well as social and economic exclusion translate into limited opportunities in economic and political spheres.

\section{Gender and Human Development}

The Gender Development Index (GDI) and Gender Empowerment Measure (GEM) have been used to measure inequality between men and women. The GDI captures inequality in terms of the same dimensions as the HDI-long and healthy life measured by life expectancy at birth, knowledge measured by adult literacy and mean years of schooling and a decent standard of living measured by GNI per capita in PPP \$. The GEM indicates the relative empowerment of women and men in various political and economic spheres. It reflects opportunities open to women rather than their capabilities in three key areas: political participation and decision-making, economic participation and decision-making, and power over economic resources. The methodologies to compute the GDI and GEM are described in table.

\section{Gender Development Index (GDI) Values in Nepal}

Gender Development Index has been computed using the arithmetic mean and the geometric mean. The score for Nepal in 2011 is 0.534 value, based on the arithmetic mean. Using the geometric mean gives a figure of 0.482 . Irrespective of these methods, the regional pattern is broadly similar. Among the ecological regions, the GDI value based on the geometric mean is the highest in the Hills at 0.564 followed by the Tarai at 0.512 and the Mountains at 0.487 . The score of GDI value are as follows:

Table 3: Comparative GDI values for ecological and development regions over time, 2001, 2006 and 2011

\begin{tabular}{|l|c|c|c|}
\hline \multicolumn{1}{|c|}{ Regions } & $\mathbf{2 0 0 1}$ & $\mathbf{2 0 0 6}$ & $\mathbf{2 0 1 1}$ \\
\hline Mountain & 0.363 & 0.423 & 0.487 \\
\hline Hill & 0.498 & 0.534 & 0.564 \\
\hline Terai & 0.450 & 0.482 & 0.512 \\
\hline Eastern Development Region (EDR) & 0.475 & 0.516 & 0.534 \\
\hline Central Development Region (CDR) & 0.467 & 0.517 & 0.551 \\
\hline
\end{tabular}




\begin{tabular}{|ll|c|c|c|}
\hline Western Development Region (WDR) & 0.477 & 0.411 & 0.546 \\
\hline $\begin{array}{l}\text { Mid-western Development Region } \\
\text { (MWDR) }\end{array}$ & 0.385 & 0.441 & 0.498 \\
\hline $\begin{array}{l}\text { Far-Western Development Region } \\
\text { (FWDR) }\end{array}$ & 0.377 & 0.447 & 0.481 \\
\hline Nepal & $\mathbf{0 . 4 5 2}$ & $\mathbf{0 . 4 9 9}$ & $\mathbf{0 . 5 3 4}$ \\
\hline
\end{tabular}

Source: UNDP, 2014

Among the development regions, a picture similar to that of the HDI emerges. The central region has the highest GDI value with 0.551 based on the arithmetic mean followed by the Western region at 0.546 and the Eastern region at 0.534 . The Far Western and MidWestern regions have the lowest values at 0.481 and 0.498 respectively, primarily due to low life expectancy and adult female literacy. A comparison of GDI values over time using the arithmetic mean shows progress nationally and in the ecological and development regions. Nationally, there is an 18 percent improvement in the GDI score between 2001 and 2011. Improvement is above the national average in the Mountains at 34.1 percent, the Mid Western region at 29.3 percent and the Far Western region at 27.5 percent. The low GDI score is mainly due to low values in all three dimensions of the index. Indicators for life expectancy at birth and mean years of schooling for both sexes are the lowest in the Mountains and the highest in the Hills. Female adult literacy is also very low in the Mountains at 37.7 percent compared to 43.3 percent in the Tarai and 56.4 percent in the Hills.

\section{Gender Empowerment Measure (GEM) Values in Nepal}

The value of the Gender Empowerment Measure (GEM) for Nepal for 2011 is 0.568 . Among ecological regions the Mountains has the lowest value at 0.483 , while the Hills has the highest at 0.572 . This is due to the former's low share of women in Parliament at 18.6 percent in mountain compared to 28.9 percent in hill and 32.9 percent for the Tarai and low combined income values as well. The score of GEM value are as follows: 
Table 4: Comparative gender empowerment measure values over time, 2001, 2006 and 2011.

\begin{tabular}{|l|c|c|c|}
\hline \multicolumn{1}{|c|}{ Region } & $\mathbf{2 0 0 1}$ & $\mathbf{2 0 0 6}$ & $\mathbf{2 0 1 1}$ \\
\hline Mountain & 0.356 & 0.468 & 0.483 \\
\hline Hill & 0.408 & 0.515 & 0.572 \\
\hline Terai & 0.372 & 0.469 & 0.563 \\
\hline Eastern Development Region (EDR) & 0.382 & 0.516 & 0.575 \\
\hline Central Development Region (CDR) & 0.407 & 0.511 & 0.573 \\
\hline Western Development Region (WDR) & 0.359 & 0.488 & 0.567 \\
\hline Mid-Western Development Region (MWDR) & 0.363 & 0.431 & 0.556 \\
\hline Far-Western Development Region (FWDR) & 0.368 & 0.456 & 0.523 \\
\hline Nepal & $\mathbf{0 . 3 9 1}$ & $\mathbf{0 . 4 9 6}$ & $\mathbf{0 . 5 6 8}$ \\
\hline
\end{tabular}

Source: UNDP, 2014.

Among development regions, the Eastern region has the highest GEM value with 0.575 followed by the Central and Western regions with 0.573 . This pattern varies from that of the GDI. The Far Western region has the lowest GEM value of 0.523 , primarily due to its low share of women in administrative and professional positions. A comparison of the GEM for 2001, 2006 and 2011 shows a rise in values in all ecological and development regions over time. Among ecological regions, the Tarai displays rapid growth between 2006 and 2011. For the development regions during the same period, GEM values improved most significantly in the Mid-Western region.

\section{Human Poverty Index (HPI) Values in Nepal}

The Human Development Index reflects the expansion of opportunities and choices the Human Poverty Index (HPI) captures the denial as a result of income and capability deprivation. The HPI value for Nepal in 2011 is 31.12. Among ecological regions, the HPI is lowest in the Hills at 29.20 and highest in the Mountains at 38.51. Both the Mountains and Tarai regions have HPI values less than the national average. Among the development regions, the value is lower than the national average only in the Western region at 27.20 and the Eastern region at 29.22. The Mid Western region has the highest rank at 36.63 which is 1.3 times higher than that of the Western region. According to the district, the highest and lowest HPI value are as follows: 
Table 4: Districts with the highest and lowest HPI values, 2001 and 2011

\begin{tabular}{|l|l|l|l|l|l|l|l|}
\hline \multicolumn{4}{|c|}{ Highest } & \multicolumn{4}{c|}{ Lowest } \\
\hline 2001 & \multicolumn{2}{c|}{$\mathbf{2 0 1 1}$} & \multicolumn{2}{c|}{2001} & \multicolumn{2}{c|}{2011} \\
\hline Humla & 63.8 & Humla & 49.26 & Kaski & 24.9 & Kaski & 16.50 \\
\hline Dolpa & 61.9 & Achham & 46.68 & Lalitpur & 25.0 & Lalitpur & 19.18 \\
\hline Mugu & 61.1 & Rautahat & 46.43 & Kathmandu & 25.8 & Bhaktapur & 19.43 \\
\hline Bajhang & 59.9 & Bajhang & 45.32 & Jhapa & 29.2 & Jhapa & 21.82 \\
\hline Achham & 59.2 & Mugu & 45.22 & Rupendehi & 29.2 & Kathmandu & 22.45 \\
\hline
\end{tabular}

Source: UNDP, 2014

High levels of human poverty in the Mid-Western and Far Western regions reflect deprivations in health, education and sanitation. In these two regions, the most deprived districts in terms of health are Dolpa, Bajura, Kalikot and Bajhang. The most deprived districts in terms of education are Rautahat, Mahottari, Humla, Sarlahi, Mugu and Siraha, where adult illiteracy rates are over 60 percent. Dailekh, Dang, Achham, Jajarkot and Salyan, mainly in the Mid-Western region are the most deprived in terms of access to safe drinking water, whereas the highest prevalence of child malnutrition is in Humla and Bajhang, where more than 60 percent of children are malnourished. There are variations by rural and urban residence and by ecological and development regions. Urban-rural differences are considerable with rural poverty nearly 1.8 times higher than urban poverty.

\section{Conclusion}

This study finds that, Nepal Human Development Reports have emphasized that inequalities between high and low HDI values for caste and ethnic groups, regional and gender disparities. It has found that Nepal's position is not good as well as the low human development regarding of income, educational attainment, ecological footprint. Human development index growth rates vary by state and ecological development region. It can be concluded that the countries that belong to the medium human development group have achieved the highest growth, but this growth is insufficient to transform them into more development HDI levels. The highest HDI ranks are in urban areas like Kathmandu district, followed by Lalitpur, which has a substantially lower rank. The $5^{\text {th }}$ highest rank is in the industrial city of Biratnagar and the 8th highest rank is in Chitwan.

Human development index, differences in educational attainment largely explain inequalities between high and low HDI values for caste and ethnic groups like Newars 
0.565, Hill Brahmin 0.557 and Medhesi Dalits 0.400. This is underscored by the low educational attainment of the Dalits in general and the Madhesi Dalits in particular and of the Muslims. Low levels of education as well as social and economic exclusion translate into limited opportunities in economic and political spheres. Gender development index underscoring the closing gap between the best and worst performing regions in the last decade. Hill has highest GDI value with 0.564 and Mountain has low with 0.487. Although gender disparities in life expectancy, education and income remain major challenges across Nepal. According to human poverty index, Dailekh, Dang, Achham, Jajarkot and Salyan, mainly in the mid-western region are the most deprived in terms of access to safe drinking water, whereas the highest prevalence of child malnutrition is in Humla and Bajhang, where more than 60 percent of children are malnourished. Therefore, Nepal needs a breakthrough and big push in their development process for accelerating the performance of human development.

\section{References}

Alamieyeseigha, D. S. P., \& Kpolovie, P. J. (2013). The making of the United States of America: Lessonsfor Nigeria. Owerri: Springfield Publishers Ltd., USA.

Atkinson, A. (2015). Inequality: What can be done?Cambridge, Harvard University Press.

Bozzano, M. (2011). Assessing gender inequality among Italian regions: An exploratory analysis. Italy. Government of Nepal (GoN). (2014). Nepal human development report 2014. United Nations Development Programme and National Planning Commission,Singh Durbar Kathmandu.

Government of Nepal (GoN). (2020). Nepal human development report 2020. United Nations Development Programme and National Planning Commission,Singh Durbar Kathmandu.

Haq, U. M. (1999). Reflections on human development. Oxford University Press, Delhi, India.

Hicks, A. D. (1997). The inequality-adjusted human development index.World Development, 25(8), 1283-1298, UK.

https://www.hdr.undp.orghttp://hdr.undp.org/en/content/human-developmentindex-hdi

Sen, A. (1987b). The standard of living. Cambridge University Press, Cambridge, UK.

Sen, A. (1999). Commodities and capabilities. Oxford University Press, New York. 
Sen, A. (2000a). A decade of human development. Journal of Human Development, 1(1), $17-23$.

Sen, A. (1999). Development as freedom. Oxford University Press, UK.

United Nations Development Program (UNDP). (2007). Gender empowerment measure. World Development Indicators Database. Washington, D.C. USA.https://hdr.undp.org/ en/media/HDR_20072008_GEM.pdf

United Nations Development Programme (UNDP). (2010). Human development report 2010: The real wealth of nations-pathways to human development. New York. https:/hdr.undp.org/en/content/human-development-report-2010

United Nations Development Programme (UNDP). (2016). Human Development Report 2016: Human development for everyone. https:/hdr.undp.org/sites/default/ files/2016 human_development_report.pdf

World Economic Forum (WEF). (2010). Global gender gap report 2010.https://www3. weforum.org/docs/WEF_GenderGap_Report_2010.pdf 